\title{
Rationale for gastrectomy with D2 lymphadenectomy in the treatment of gastric cancer
}

\author{
Álvaro Díaz de Liaño ${ }^{1}$, Concepción Yarnoz $^{1}$, Rubén Aguilar ${ }^{2}$, Cristina Artieda $^{1}$, and Héctor Ortiz ${ }^{1}$ \\ ${ }^{1}$ Esophagogastric Unit, General and Digestive Surgery Department, Hospital Virgen del Camino, c/o Pintor Maeztu 2, 8C, 31008 Pamplona, \\ Navarra, Spain \\ ${ }^{2}$ General Surgery Department, Hospital Central Instituto de Previsión Social, Asunción, Paraguay
}

\begin{abstract}
Background. In the surgical management of gastric cancer, D2 lymphadenectomy aims to reduce the incidence of locoregional relapse, and to increase patient survival.

Methods. A prospective study was made of 126 consecutive patients operated upon for gastric cancer, with gastrectomy and D2 lymphadenectomy. Hospital morbidity and mortality, relapses, and patient survival after 5 years were studied.

Results. The overall hospital mortality rate was $1.6 \%$, with a mortality of $2.1 \%$ in the patients submitted to total gastrectomy. The overall morbidity rate was $29.4 \%$. Dehiscence of the esophagojejunal anastomosis was recorded in $1.6 \%$. The median follow-up was 73.6 months. Relapses were observed in $37 \%$ of the patients $(76 \%$ in the first 2 years). Overall actuarial survival after 5 years was $52.3 \%$, and 5-year survival in the patients with $\mathrm{R} 0$ resection with positive $\mathrm{N} 2$ lymph nodes according to the Japanese classification was $26.5 \%$.

Conclusion. Our results show that D2 lymphadenectomy can be performed with low morbidity-mortality, and a 5-year survival of more than $50 \%$. The procedure offers benefit in terms of survival for a certain percentage of patients with positive level N2 lymph nodes.
\end{abstract}

Key words Gastric cancer . D2 lymphadenectomy . Morbidity-mortality $\cdot$ Recurrence $\cdot$ Survival

\section{Introduction}

The ultimate aim of all surgeons treating gastric cancer is to heal their patients, or at least to achieve the longest survival possible, with acceptable quality of life.

The overall 5-year survival rate among patients with resectable gastric cancer ranges from $10 \%$ to $30 \%$ in the western world. In contrast, Japanese publications report

Offprint requests to: A. Díaz de Liaño

Received: January 16, 2008 / Accepted: April 12, 2008 a marked improvement in survival (between 50\% and $62 \%$ ), largely attributed to lymph node resection known as "D2 lymphadenectomy" [1]. The randomized prospective studies made by the Dutch Gastric Cancer Group and the Medical Research Council, comparing patients submitted to D2 lymphadenectomy with those submitted to D1 gastrectomy, concluded that D2 lymphadenectomy caused greater morbidity and mortality, without benefit in terms of survival. The procedure therefore was not recommended on a routine basis $[2,3]$.

These conclusions have been repeatedly questioned, however, for methodological reasons, among others. This and the publication of studies showing the advantages of D2 lymphadenectomy have generated uncertainty regarding an ideal lymphadenectomy for the management of these patients [4-17].

Moreover, other studies suggest that surgeon expertise not only plays an important role in reducing surgical morbidity and mortality but also contributes substantially to improving survival [18].

Gastric cancer mortality is largely attributable to relapse of the disease, manifesting in different ways or in more than one location simultaneously [19].

Some authors consider gastric cancer relapse and patient survival to depend on both the stage of the disease at the time of diagnosis and on the extent of surgery [4].

The present study examined whether D2 lymphadenectomy associated with surgery for gastric cancer can be performed with morbidity and mortality outcomes that justify the procedure, and, moreover, whether the procedure offers benefit in terms of patient survival.

The study presents the results obtained with gastrectomy and D2 lymphadenectomy performed over a period of time at the Department of General and Digestive Surgery (Esophagogastric Unit) of the Virgen del Camino Hospital (Pamplona, Navarre, Spain). 


\section{Patients, materials, and methods}

A prospective study was made of 126 consecutive patients diagnosed with gastric adenocarcinoma in the absence of distant metastases. The patients were submitted to gastrectomy and D2 lymphadenectomy with curative intent between April 1998 and March 2006. Patients with a histopathological diagnosis other than adenocarcinoma were excluded, as were those with synchronous neoplasms, and those with tumors located at the esophagogastric junction. There were no exclusions due to comorbidity or age, except for those patients for whom surgery did not intend to be radical due to the extent of illness, or patients for whom surgery was exclusively palliative. Patients with tumors localized in the gastric stump were included in this study in order to record all consecutive patients during the time period of this study.

Distal subtotal gastrectomy was reserved for those patients with tumors measuring under $3 \mathrm{~cm}$ in longitudinal diameter, located in the distal antrum, corresponding to the Lauren intestinal type, and which, on macroscopic examination, appeared not to invade the gastric serosa. The remaining patients underwent total gastrectomy.

Resection was extended to neighboring organs when tumor invasion was suspected. Splenectomy was performed in patients with advanced proximal tumors with suspected splenic infiltration, or with apparently invaded splenic hilar lymph nodes. A distal pancreatectomy was performed in patients with suspected tumor infiltration or metastatic disease in the lymph nodes of the splenic artery chain.

Lymph node dissection was carried out according to the recommendations of the Japanese Research Society for Gastric Cancer (JRSGC). The removed lymph nodes corresponded to levels 1 and 2 (modified by dissection of lymph node stations $7,8,9$, and 11 without splenectomy and including group 12).

Disease staging was based on the TNM classification included in the fifth edition (2005) of the TNM atlas: illustrated guide to the TNM classification of malignant tumors, of the International Union Against Cancer (UICC) and the American Joint Committee on Cancer (AJCC) [20].

Follow-up included clinical laboratory and ultrasound examinations of all patients on a semestrial basis during the first 2 years after surgery, and yearly thereafter. In addition, when relapse was suspected, endoscopy with biopsy, computed tomography (CT), and contrast radiography of the digestive tract were performed on a patient-individualized basis. Laboratory tests included the tumor markers carcinoembryonic antigen (CEA) and carbohydrate antigen (CA) 19-9, among other parameters.
Recurrences were classified as locoregional, peritoneal, or distant. Locoregional recurrences, in turn, included those located in the surgical bed, retroperitoneal lymph nodes of the upper abdomen, or in the gastric stump or anastomotic zone. Peritoneal recurrences included those affecting the ovaries (Krukenberg tumor), carcinomatosis, and positive cytology. Finally, distant recurrences were those detected in other nonregional lymph nodes or other organs.

Overall actuarial survival after 5 years was determined, and actuarial survival after 5 years according to AJCC stages was also recorded. Finally, a study was made of 5-year survival in the patients with $\mathrm{R} 0$ resection with positive level N2 lymph nodes (according to the Japanese classification).

\section{Statistical analysis}

The SPSS version 12.0.1 statistical package for Microsoft Windows (2003; SPSS, Chicago, IL, USA) was used for statistical analysis. Values for qualitative variables were given as percentages and those for quantitative variables were given as medians and interquartile ranges (IQRs). Survival curves were calculated using the Kaplan-Meier method, and the log-rank test was employed for comparison. $P$ values of under 0.05 were considered statistically significant.

\section{Results}

Tables 1 and 2 list the characteristics of the patients included in the series, along with the complications recorded and the patients requiring reintervention.

In this series, resection of other organs was exclusively due to the suspicion of tumor invasion; in those patients with pancreatic or spleen resection, apart from this cause, resection was performed in patients with tumor proximity to and suspicion of lymph node invasion of groups 10 and 11 . In the 22 patients in whom a splenectomy was carried out, 20 were for tumors located in the superior and middle thirds of the stomach (16 patients had T3/T4 tumors and 4 tumors were localized near the splenic hilum with suspicion of lymphatic invasion); the other 2 patients had stump gastric cancers. Histopathological study showed there was tumoral invasion of the lymph nodes of the splenic hilum in 8 patients. Pancreatectomy was performed in 9 patients with T3/T4 tumors and tumoral invasion was confirmed in 3 . In the remaining patients with $\mathrm{T} 3 / 4$ tumors, both the spleen and the tail of the pancreas were preserved.

There were 37 patients with complications (29.4\%), and some of them presented more than one complication. There were 12 surgical reinterventions and 
Table 1. Characteristics of the 126 consecutive patients (gastrectomy with D2 lymphadenectomy)

\begin{tabular}{|c|c|}
\hline Median age, in years (IQR) & $70(15.5)$ \\
\hline \multicolumn{2}{|l|}{$\operatorname{Sex}(\%)$} \\
\hline Male & $89(70.6)$ \\
\hline \multicolumn{2}{|l|}{$\operatorname{ASA}(\%)^{\mathrm{a}}$} \\
\hline I & $10(7.9)$ \\
\hline II & $35(27.8)$ \\
\hline III & 78 (61.9) \\
\hline IV & $3(2.4)$ \\
\hline \multicolumn{2}{|l|}{ Lauren type (\%) } \\
\hline Intestinal & 77 (61.1) \\
\hline Diffuse & $42(33.3)$ \\
\hline Indeterminate & $7(5.6)$ \\
\hline \multicolumn{2}{|l|}{ Tumor location (\%) } \\
\hline Upper third & $36(28.6)$ \\
\hline Middle third & $35(27.8)$ \\
\hline Lower third & $51(40.5)$ \\
\hline Gastric stump & $4(3.2)$ \\
\hline \multicolumn{2}{|l|}{ Type of gastrectomy (\%) } \\
\hline Total & $95(75.4)$ \\
\hline Subtotal & $31(24.6)$ \\
\hline Median tumor size, in cm (IQR) & $5(4)$ \\
\hline \multicolumn{2}{|l|}{ Associated surgery (\%) } \\
\hline Splenectomy & $22(17.5)$ \\
\hline Left pancreatectomy & $9(7.1)$ \\
\hline Colectomy & $4(3.2)$ \\
\hline Hepatectomy & $4(3.2)$ \\
\hline Nephrectomy & $1(0.8)$ \\
\hline \multicolumn{2}{|l|}{ Surgical margin infiltration (\%) } \\
\hline Upper & $6(4.8)$ \\
\hline Lower & $5(4.0)$ \\
\hline \multicolumn{2}{|l|}{ Type of intervention (\%) } \\
\hline R0 & $99(78.6)$ \\
\hline R1 & $27(21.4)$ \\
\hline \multicolumn{2}{|l|}{ Infiltration of other organs (\%) } \\
\hline Pancreas & $3(2.4)$ \\
\hline Colon & $4(3.2)$ \\
\hline Liver & $1(0.8)$ \\
\hline Spleen & $1(0.8)$ \\
\hline Esophageal hiatus & $1(0.8)$ \\
\hline Kidney & $1(0.8)$ \\
\hline Median no. of lymph nodes removed (IQR) & $32.5(16)$ \\
\hline \multicolumn{2}{|l|}{ According to levels (N) of the JRSGC, median (IQR) } \\
\hline $\mathrm{N} 1$ & $24(13)$ \\
\hline N 2 & $8(5)$ \\
\hline \multicolumn{2}{|l|}{$\mathrm{N}$ stage $(\%)$} \\
\hline $\mathrm{N} 0^{\mathrm{b}}$ & $51(40.5)$ \\
\hline $\mathrm{N} 1^{\mathrm{c}}$ & $42(33.3)$ \\
\hline $\mathrm{N} 2^{\mathrm{d}}$ & $17(13.5)$ \\
\hline $\mathrm{N} 3^{\mathrm{e}}$ & $16(12.7)$ \\
\hline \multicolumn{2}{|l|}{ Staging (\%) } \\
\hline 0 & $6(4.8)$ \\
\hline IA & $22(17.5)$ \\
\hline IB & $28(22.2)$ \\
\hline II & $13(10.3)$ \\
\hline IIIA & $21(16.7)$ \\
\hline IIIB & $12(9.5)$ \\
\hline IV & $24(19.0)$ \\
\hline
\end{tabular}

IQR, interquartile range

${ }^{\text {a }}$ Physical condition classification according to the American Society of Anesthesiologists

${ }^{\mathrm{b}}$ No positive nodes

${ }^{\mathrm{c}}$ One to 6 positive nodes

${ }^{\mathrm{d}}$ Seven to 15 positive nodes

${ }^{\mathrm{e}}$ More than 15 positive nodes 
Table 2. Postoperative complications $(n=126)$ and reoperated patients $(n=12)$

\begin{tabular}{lr} 
Complications (\%) & \\
Nonabdominal & \\
Respiratory & $13(10.3)$ \\
Stroke & $1(0.8)$ \\
Heart failure & $1(0.8)$ \\
Others & $11(8.7)$ \\
Abdominal & \\
Intestinal obstruction & $7(5.6)$ \\
Bleeding & $4(3.2)$ \\
Peritonitis & $1(0.8)$ \\
Evisceration/wall abscess & $3(2.4)$ \\
Abdominal abscess & $4(3.2)$ \\
Anastomotic dehiscence & $4(3.2)$ \\
Esophagojejunal & $2(1.6)$ \\
$\quad$ Gastrojejunal & $1(0.8)$ \\
Duodenal stump & $1(0.8)$ \\
Pancreatic fistula & $1(0.8)$ \\
Surgical reinterventions (\%) & \\
Dehiscence & $2(1.6)$ \\
Abscess & $1(0.8)$ \\
Bleeding & $4(3.2)$ \\
Intestinal obstruction & $3(2.4)$ \\
Others & $2(1.6)$ \\
\hline
\end{tabular}

in all cases, these were in patients with total gastrectomies.

A systematic water-soluble contrast X-ray test was performed on the seventh postoperative day. No anastomotic leak was observed in the four patients with abdominal abscess. One of these patients needed a laparotomy for drainage; the three other patients were satisfactorily treated by percutaneous techniques. One patient had postoperative peritonitis due to a needle catheter jejunostomy leak, found at the surgical reoperation. There were two patients with esophagojejunal dehiscence, one patient needed a new laparotomy for drainage and the other was treated with percutaneous drainage. In the one patient with gastrojejunal anastomotic leak, the leak was successfully managed conservatively with surgical drainage and medical treatment. One patient had a duodenal stump leak, and was reoperated on with satisfactory recovery. One patient had a pancreatic fistula, which resolved in a week.

The overall mortality of this series was $1.6 \%$ (two patients); in both patients a total gastrectomy had been performed (total gastrectomy mortality, 2.1\%). One patient, who was 64 years old with ischemic cardiopathy, coronary bypass, and severe chronic obstructive pulmonary disease, had presented with respiratory distress secondary to pneumonia, and died on the thirtieth postoperative day with no evidence of intraabdominal complication. The other patient, who was 70 years old and had diabetes mellitus and chronic obstructive pulmonary disease, had a post-transfusional shock on the

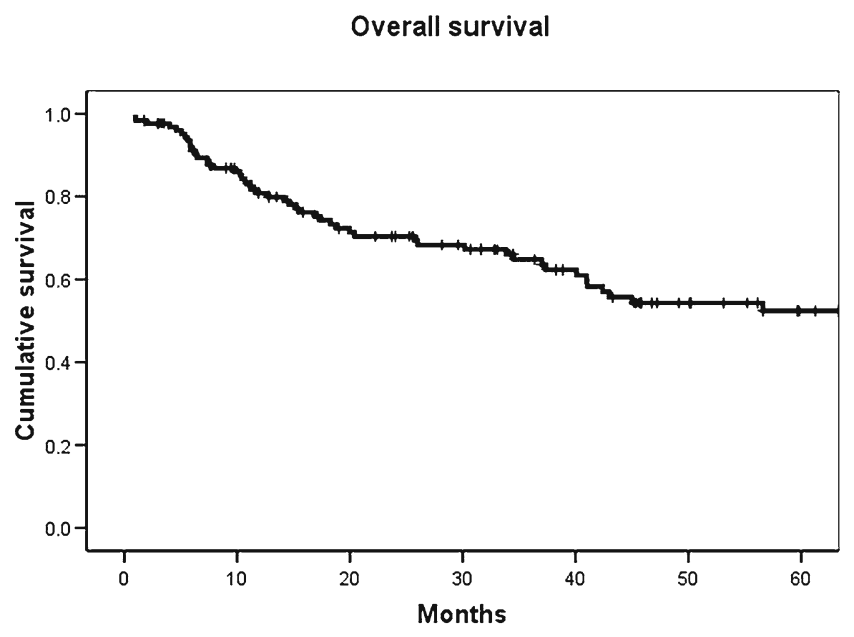

Fig. 1. Overall actuarial survival

twenty-fourth postoperative day. An autopsy did not find any intraabdominal complication. Neither of these two patients had an anastomotic leak (esophagojejunal anastomosis mortality, $0 \%$ ).

The median duration of follow-up was 73.6 months. During follow-up of the 124 patients, we detected disease relapse in 46 patients $(37 \%) ; 15$ presented with distant relapse, 14 with local relapse, and 12 with peritoneal relapse. The other 5 patients showed disease relapse in more than one location (3 local and distant, and 2 local and peritoneal). During the first 2 years, relapses were observed in 35 patients $(76 \%)$. Of these 35 patients, 11 suffered local disease recurrence, 10 presented with peritoneal recurrence, and 14 showed distant spread.

The overall actuarial survival rate after 5 years was $52.3 \%$ (Fig. 1). Forty patients died of gastric cancer, 13 patients died of other causes (5, other neoplasms; 3 , acute myocardial infarction; 2, postoperative deaths; 2 , strokes; 1 , acute rupture of an abdominal aortic aneurysm), and 73 were alive. Due to the demographic and geographic features of our population and taking into account that this is a public hospital, we have not had any loss of follow-up. The median follow-up for the surviving patients was 38.3 months (IQR, 45.8). The survival curves of the patients grouped according to AJCC pathological stage are shown in Fig. 2.

In the 99 patients in whom an R0 resection was achieved (70 with total gastrectomies and 29 with subtotal gastrectomies) there were three cases of anastomotic leak (one of them was esophagojejunal). Hospital mortality was $2 \%$ and the 5 -year actuarial survival was $65 \%$. In this group, there were 16 patients with positive level N2 lymph nodes, and these 16 patients had a 5year survival rate of $26.5 \%$ (Fig. 3 ). 


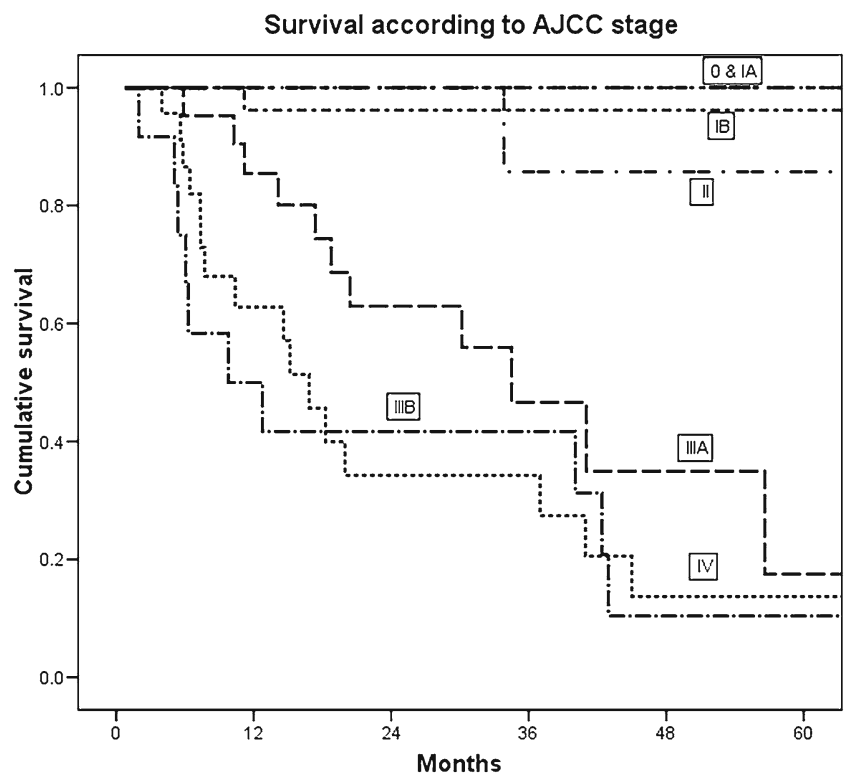

Fig. 2. Survival according to American Joint Committee on Cancer $(A J C C)$ stage

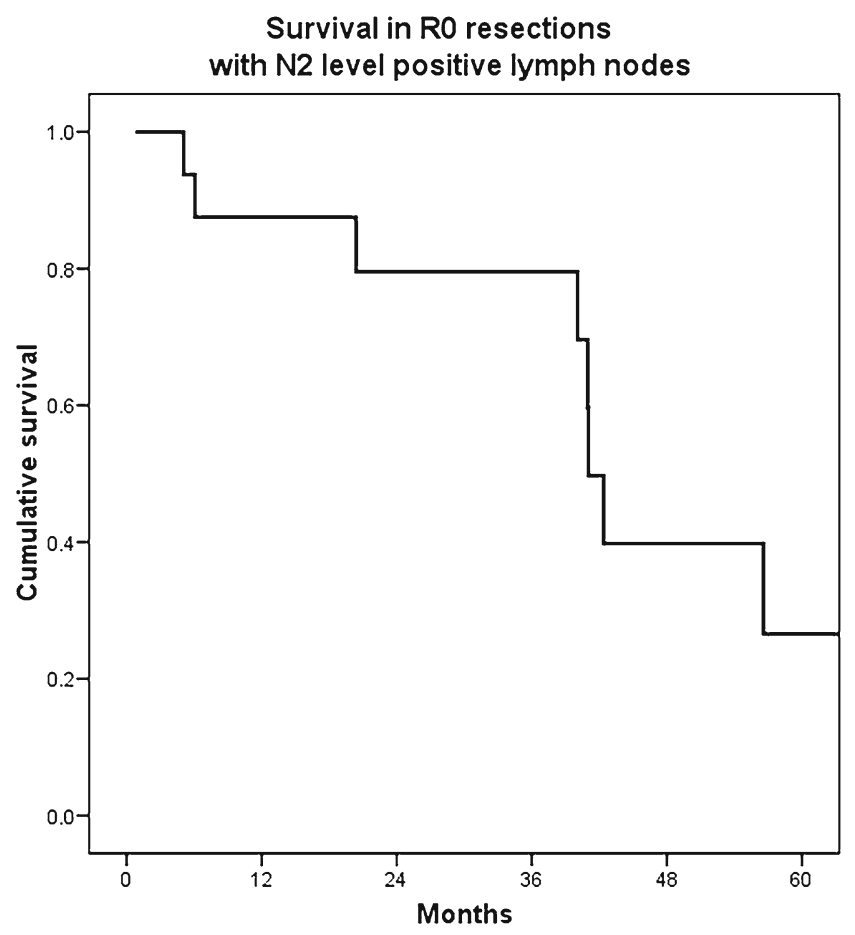

Fig. 3. Survival in patients with $\mathrm{R} 0$ resections with positive N2 level lymph nodes

\section{Discussion}

In a previous article, we reviewed, retrospectively, the morbidity and mortality of total gastrectomy in a series of 203 patients operated on at our institution between 1980 and 2000 [21]. These surgical interventions were performed by surgeons with different degrees of experience in esophagogastric surgery. In most of the patients (90.8\%) gastrectomy was associated with D1 lymphadenectomy, with a postoperative morbidity of $33.7 \%$ and mortality of $7.2 \%$. The incidence rate of esophagojejunal dehiscence was $7.8 \%$, with dehiscence mortality of $37.5 \%$, and the incidence rate of intraabdominal abscess was $7.3 \%$, with abscess mortality of $33.3 \%$ [21]. These results encouraged us to create a unit of surgeons specifically dedicated to esophagogastric surgery.

The overall morbidity rate in the present series was $29.4 \%$. We consider this figure to be reasonable, because it includes all the recorded complications, and is lower than the percentages reported by other authors $[2,3,5$, $6,22]$, though some series have yielded overall morbidity rates of under $12 \%[7,23,24]$. The most common nonabdominal complications in our series were of a respiratory nature, in agreement with many other literature sources [3, 7-14, 22-24].

Among the abdominal complications, the anastomotic leakage rates reported in the literature range from $2.1 \%$ to more than $8 \%$ [3,7-14,22,24]. The overall incidence of dehiscence in our series $(3.2 \%)$ included not only esophagojejunal anastomotic dehiscences but also all other anastomotic and suture dehiscences. Most sources in the literature do not provide details on the incidence of esophagojejunal anastomotic leakage, which reached $1.6 \%$ in our series - in agreement with the findings of other studies that have published such information $[12,23]$.

The overall mortality rate in our series was $1.6 \%$, with a procedure-related mortality rate of between $0 \%$ for subtotal gastrectomy and $2.1 \%$ for total gastrectomy. These figures are comparable to those of other surgical teams with specialization and training in these operations, and we think that, indirectly, these results reinforce our belief in recommending the performance of gastrectomy with D2 lymphadenectomy in specialized units $[7,8,10,15,23-26]$. We would also like to remark that we believe in the importance of performing a D2 lymphadenectomy without splenectomy in order to achieve these postoperative morbidity and mortality figures.

The incidence of disease relapse varies greatly among the different series published in the literature. This is due to a number of factors, including the extent of surgery and the tumor stage at the time of the operation. Other acknowledged factors are surgeon expertise and the number of operations performed at centers where such surgery is carried out. Accordingly, the published relapse rates range from $20 \%$ to more than $60 \%$. We consider our recurrence rate $(37 \%)$ to be low, because it includes both $\mathrm{R} 0$ and $\mathrm{R} 1$ patients, unlike many other studies that include only $\mathrm{R} 0$ patients $[16,19$, 27-33]. 
According to the authors that advocate such surgery, the performance of a D2 or more extensive lymphadenectomy offers improved locoregional disease control, and causes most relapses to be peritoneal and hematogenous $[4,16,19,27,33]$.

It is generally accepted that most relapses occur within the first 2 years after curative surgery for gastric cancer [4, 30-35]. Yoo et al. [19], on classifying relapse into early and late groups (according to whether relapse occurred before or after 2 years), found $73 \%$ of all disease relapses to occur early. D'Angelica et al. [29], in turn, reported a higher relapse rate, of $79 \%$, in the first 2 years after surgery - this figure reached $94 \%$ before the fourth year In our series, recurrence within the first 2 years after surgery was seen in $76 \%$ of the patients.

Gastric cancer survival according to the type of surgery performed has been the subject of many studiesincluding those of Bonenkamp et al. [2] and Cuschieri et al. [3], who recommended the obviation of routine D2 gastrectomy due to its high morbidity and mortality, and because the overall 5-year survival in their group of D2 lymphadenectomized patients was not significantly different from that of the group submitted to more conservative surgery. Other authors have also reported overall 5-year survival rates of under $50 \%$, with results in the range of $30 \%-47 \%[5,10,11$, $25,36]$.

Our overall survival rate $(53.2 \%)$ is similar to the percentages reported by other authors, though some studies have reported rates of up to $68 \%$. We consider that the great variation in published results may be influenced by differences in the treated patient groups, as in some studies more than $66 \%$ of the patients had disease that corresponded to stages I and II $[7,13-15$, 26, 37].

Likewise, many series have reported the growing influence of the presence of positive lymph nodes, and their number, in determining poorer 5-year patient survival $[2,14,15,17,25,37-39]$.

Our $26.5 \%$ survival rate after 5 years in the operated patients with positive level N2 lymph nodes (groups 7 to 12 of the Japanese classification) and $\mathrm{R} 0$ resection points to a possible beneficial effect of such surgery in a proportion of these patients. Similar observations have already been reported in other studies, with 5-year survival rates for this particular patient subgroup in the range of $17 \%-33.4 \%[15,40-42]$.

In conclusion, the results obtained in our series of patients submitted to gastrectomy with D2 lymphadenectomy suggest that this technique offers low morbidity-mortality and acceptable 5-year survival rates of more than $50 \%$. In addition, tumor staging is improved, and locoregional recurrences are reduced. We consider it essential for such surgery to be performed by specialized surgeons - this, in turn, making it necessary to concentrate the patients at certain units and centers. Also, of note, there is evidence to suggest that D2 lymphadenectomy offers a beneficial effect in terms of survival for a certain proportion of patients.

\section{References}

1. Dicken BJ, Bigam DL, Cass C, Mackey JR, Joy AA, Hamilton SM. Gastric adenocarcinoma: review and considerations for future directions. Ann Surg 2005;241:27-39.

2. Bonenkamp J, Hermans J, Sasako M, van de Velde CJ, Welvaart $\mathrm{K}$, Songun I, et al. Extended lymph-node dissection for gastric cancer. N Engl J Med 1999;340:908-14.

3. Cuschieri A, Fayers P, Fielding J, Craven J, Bancewicz J, Joypaul $\mathrm{V}$, et al. Postoperative morbidity and mortality after D1 and D2 resections for gastric cancer: preliminary results of the MRC randomized controlled surgical trial. Lancet 1996;347:995-9.

4. Roukos D, Kappas A. Limitations in controlling risk for recurrence after curative surgery for advanced gastric cancer are now well explained by molecular-based mechanisms. Ann Surg Oncol 2001;8:620-1.

5. Desai A, Pareek M, Nightingale P, Fielding J. Improving outcomes in gastric cancer over 20 years. Gastric Cancer 2004;7:196203.

6. Sasako M. Risk factors for surgical treatment in the Dutch gastric cancer trial. Br J Surg 1997;84:1567-71.

7. Roviello F, Marrelli D, Morgagni P, de Manzoni G, Di Leo A, Vindigni C, et al. Survival benefit of extended D2 lymphadenectomy in gastric cancer with involvement of second level lymph nodes: a longitudinal multicenter study. Ann Surg 2002;9: 894-900.

8. Siewert JR, Böttcher K, Stein H, Roder JD. Relevant prognostic factors in gastric cancer: 10-year results of the German Gastric Cancer Study. Ann Surg 1998;228:449-61.

9. Siewert JR, Böttcher K, Roder JD, Busch R, Heimanek P, Meyer HJ. Prognostic relevance of systematic lymph node dissection in gastric carcinoma. Br J Surg 1993;80:1015-8.

10. Csendes A, Burdiles P, Rojas J, Braghetto I, Diaz JC, Maluenda F. A prospective randomized study comparing D2 total gastrectomy versus $\mathrm{D} 2$ total gastrectomy plus splenectomy in 187 patients with gastric carcinoma. Surgery 2002;131:401-7.

11. Bittner R, Butters M, Ulrich M, Uppenbrink S, Beger HG. Total gastrectomy: updated operative mortality and long-term survival with particular reference to patients older than 70 years of age. Ann Surg 1996;224:37-42.

12. Zilberstein B, da Costa Martins B, Jacob CE, Bresciani C, Lopasso FP, de Cleva R, et al. Complications of gastrectomy with lymphadenectomy in gastric cancer. Gastric Cancer 2004;7:2549.

13. Lewis WG, Edwards P, Barry JD, Khan S, Dhariwal D, Hodzovic I, et al. D2 or not D2? The gastrectomy question. Gastric Cancer 2002;5:29-34.

14. Roder JD, Böttcher K, Siewert JR, Busch R, Hermanek P, Meyer HJ. Prognostic factors in gastric carcinoma. Results of the German Gastric Carcinoma Study 1992. Cancer 1993;72:2089-97.

15. Roukos D, Lorentz M, Encke A. Evidence of survival benefit of extended (D2) lymphadenectomy in Western patients with gastric cancer based on a new concept: a prospective long-term follow-up study. Surgery 1998;123:573-8.

16. Kappas A, Roukos D. Quality of surgery determinant for the outcome of patients with gastric cancer. Ann Surg Oncol 2002;9: 828-30.

17. Hartgrink HH, van de Velde CJ, Putter H, Bonenkamp JJ, Klein Kranenbarg E, Songun I, et al. Extended lymph node dissection for gastric cancer: who may benefit? Final results of the 
randomized Dutch Gastric Cancer Group trial. J Clin Oncol 2004;22:2069-77.

18. Birkmeyer JD, Stukel TA, Siewers AE, Goodney PP, Wennberg DE, Lucas FL. Surgeon volume and operative mortality in United States. N Engl J Med 2003:349:2117-27.

19. Yoo CH, Noh SH, Shin DW, Choi SH, Min JS. Recurrence following curative resection for gastric carcinoma. Br J Surg 2000; 87:236-42.

20. Wittekind $\mathrm{CH}$, Greene FL, Hutter RVP, Klimpfinger M, Sobin LH, editors. TNM atlas: illustrated guide to the TNM classification of malignant tumors. 5th ed. Heidelberg Berlin New York Tokyo: Springer; 2005.

21. Díaz de Liaño A, Ciga MA, Oteiza F, Aizcorbe M, Cobo F, Trujillo R. Factors involved in morbidity and mortality of total gastrectomy for gastric cancer. Rev Oncol 2002;4:265-70.

22. Dent D, Madden M, Price S. Randomized comparison of R1 and R2 gastrectomy for gastric carcinoma. Br J Surg 1988;75:110-2.

23. Bozzetti F, Marubini E, Bonfanti G, Miceli R, Piano C, Crose N, et al. Total versus subtotal gastrectomy: surgical morbidity and mortality rates in a multicenter Italian randomized trial. Ann Surg 1997;226:613-20.

24. Sano T, Katai H, Sasako M, Maruyama K. One thousand consecutive gastrectomies without operative mortality. Br J Surg 2002;89: 123.

25. Martin R, Jaques D, Brennan M, Karpeh M. Extended local resection for advanced gastric cancer: increased survival versus increased morbidity. Ann Surg 2002;236:159-65.

26. Kodera Y, Yamamura Y, Shimizu Y, Torii A, Hirai T, Yasui K, et al. Lack of benefit of combined pancreaticosplenectomy in D2 resection for proximal-third gastric carcinoma. World J Surg 1997; 21:622-8.

27. Maehara Y, Hasuda S, Koga T, Tokunaga E, Kakeji Y, Sugimachi $\mathrm{K}$. Postoperative outcome and sites of recurrence in patients following curative resection of gastric cancer. Br J Surg 2000; 87:353-7.

28. Böhner H, Zimmer T, Hopfenmüller W, Berger G, Buhr HJ. Detection and prognosis of recurrent gastric cancer. Is routine follow-up after gastrectomy worthwhile? Hepatogastroenterology 2000;47:1489-94.

29. D'Angelica M, Gonen M, Brennan MF, Turnbull AD, Bains M, Karpeh MS. Patterns of initial recurrence in completely resected gastric adenocarcinoma. Ann Surg 2004;240:808-16.

30. Schwarz R, Zagala-Nevarez K. Recurrence patterns after radical gastrectomy for gastric cancer: factors and implications for postoperative adjuvant therapy. Ann Surg Oncol 2002;9:394400.

31. Bennett JJ, Gonen M, D'Angelica M, Jaques DP, Brennan MF, Coit DG. Is detection of asymptomatic recurrence after curative resection associated with improved survival in patients with gastric cancer? J Am Coll Surg 2005;201:503-10.

32. Marrelli D, Roviello F, de Manzoni G, Morgagni P, Di Leo A, Saragoni L, et al. Different patterns of recurrence in gastric cancer depending on Lauren's histological type: longitudinal study. World J Surg 2002;26:1160-5.

33. Marrelli D, De Stefano A, de Manzoni G, Morgagni P, Di Leo A, Roviello F. Prediction of recurrence after radical surgery for gastric cancer. A scoring system obtained from a prospective multicenter study. Ann Surg 2005;241:247-55.

34. Averbach A, Jacquet P. Strategies to decrease the incidence of intra-abdominal recurrence in resectable gastric cancer. Br J Surg 1996;83:726-33.

35. Shchepotin I, Evans SR, Shabahang M, Cherny V, Buras RR, Zadorozhny A, et al. Radical treatment of locally recurrent gastric cancer. Am Surg 1995;61:371-6.

36. Karpeh M, Leon L, Klimstra D, Brennan M. Lymph node staging in gastric cancer: is location more important than number? An analysis of 1038 patients. Ann Surg 2000;232:362-71.

37. Rosenberg R, Nekarda H, Bauer P, Schenck U, Hoefler H, Siewert JR. Free peritoneal tumour cells are an independent prognostic factor in curatively resected stage IB gastric carcinoma. Br J Surg 2006;93:325-31.

38. Oka M, Yoshino S, Hazama S, Shimoda K, Suzuki M, Suzuki T. Prognosis significance of regional lymph node reaction after curative resection of advanced gastric cancer. Br J Surg 1992;79: 1091-4.

39. Kranenbarg E, Hermans J, van Krieken J, Van de Velde C. Evaluation of the 5th edition of the TNM classification for gastric cancer: improved prognostic value. Br J Cancer 2001;84:64-71.

40. Roukos D, Paraschou P. Extended lymph-node dissection in gastric cancer: standard, selective or unnecessary procedure? Hepatogastroenterology 2000;47:904-6.

41. Seto Y, Nagawa H, Muto T. Results of extended lymph node dissection for gastric cancer cases with $\mathrm{N} 2$ lymph node metastasis. Int Surg 1997:82:257-61.

42. Fujii M, Sasaki J, Nakajima T. State of the art in the treatment of gastric cancer: from the 71st Japanese Gastric Cancer Congress. Gastric Cancer 1999;2:151-7. 